\section{Diagnosticar e prescrever Médicos que formaram o Brasil}

HOCHMAN, Gilberto \& LIMA, Nísia Trindade (orgs). Médicos intérpretes do Brasil. São Paulo, Hucitec, 2015. $640 \mathrm{pp}$.

\section{Andre Bittencourt}

Um antropólogo, um presidente do Brasil e um importante escritor de ficção entram em um bar. Se fossemos contar uma piada, provavelmente sua punch line se daria pela caricatura das diferenças instauradas no improvável encontro dos três personagens, tão díspares. Mas, fique tranquilo o leitor, não contaremos piada alguma. Isso porque o antropólogo, o presidente e o ficcionista em questáo poderiam muito bem conversar, com a maior propriedade, sobre assuntos... médicos. É o que lemos em Médicos intérpretes do Brasil (Hucitec, 2015), organizado pelos cientistas sociais e pesquisadores da Fiocruz Nísia Trindade Lima e Gilberto Hochman, livro que apresenta o perfil de 29 importantes médicos brasileiros (nem todos eles reconhecidos pelo trabalho na área) com a intenção de atingir um público universitário mais amplo, não restrito somente a especialistas. Como já vemos pelo título, há ainda outro ingrediente fundamental: todos os personagens estudados foram a um só tempo médicos e argutos leitores do Brasil e de suas dinâmicas e impasses sociais, culturais, políticos e institucionais.

Um primeiro destaque da obra é sua forma de organização. Para cada médico-intérprete selecionado um texto escrito por um especialista reúne tanto aspectos de sua trajetória quanto de suas principais ideias, sempre com a preocupação de localizá-las em seu contexto original. Metodologicamente, ao proceder dessa forma, os artigos trabalham os limites impostos pelos debates médicos e sociais da época, mas também apontam para as transgressões e linhas de fuga, ou, o que é mais interessante (e recorrente no livro), mostram como esses dois elementos caminham juntos, em necessária tensão. Além do mais - e aqui um diferencial significativo da publicaçấo -, o leitor tem acesso a pequenos textos dos próprios médicos, que podem ser lidos lado a lado com o registro analítico, permitindo que nos aproximemos mais diretamente das questóes estudadas.
Em certa medida, Médicos intérpretes do Brasil poderia muito bem dar lugar a dois bons livros distintos, um de análise de ideias e outro simplesmente reunindo textos clássicos (e alguns desconhecidos e inusitados) de médicos importantes que uniram suas reflexões científicas a amplos panoramas da sociedade brasileira. O fato de esses dois livros possíveis serem apenas um, tão organicamente suturado (os artigos dos especialistas se detêm, mas não se resumem, ao texto reproduzido), confere não apenas originalidade à empreitada, mas abre um caminho promissor para experiências semelhantes.

A maior virtude da obra, no entanto, está em seu recorte analítico. Em um momento em que resta pouca margem para discutir o aparentemente inexorável processo de especialização das ciências, quando os discursos tecnicista e tecnocrático grassam e as práticas de biopoder tornaram-se, já há muito, soberanas, colocar lado a lado a ciência médica e suas interpretaçóes provoca um efeito interessante e algo desestabilizador. Ao sociologizar e historicizar grandes modelos interpretativos que, literalmente, diagnosticaram e prescreveram o que era normal ou patológico, são ou doente, científico ou supersticioso, civilizado ou atrasado, conseguimos perceber mais claramente o caráter nada transparente e, mais do que isso, essencialmente conflituoso das próprias definições que trabalham com estatutos de cientificidade que se querem imunes aos seus contextos sociais e epistemológicos. E não se trata de apontar como teses do passado tornaram-se ultrapassadas com o "progresso da ciência", mas como em sua própria contemporaneidade disputavam espaço com outras interpretações, muitas vezes diametralmente opostas.

Os organizadores ressaltam, na introdução do livro, que, se a utilização de metáforas médicas é praticamente onipresente desde o século XIX nas diferentes modalidades de interpretação do Brasil, foi nas primeiras décadas do século XX que o pensamento médico sistematicamente deixou sua marca nas representaçóes da sociedade brasileira, especialmente a partir de uma poderosa imagem: o Brasil como imenso hospital. Tomemos, portanto, esse mote como eixo. O termo aparece pela primeira vez em 1916, em um discurso de Miguel Pereira que o leitor poderá examinar no capítulo dedicado 
ao autor, e traz inscritas as clássicas oposiçóes litoral/sertão e rural/urbano que povoam o imaginário brasileiro pelo menos desde o Império e ganharam sua forma mais complexa com a obra máxima de Euclides da Cunha, publicada pouco mais de uma década antes, em 1902 (Lima, 2013). O Brasil doente, na fala de Miguel Pereira, é sobretudo aquele do sertão, esquecido pelos poderes públicos e sujeito à falta de higiene e saneamento.

Apesar da forte rotinização nos meios intelectuais brasileiros da Primeira República, essa interpretação não foi nem absolutamente original e, muito menos, pacífica, como podemos ler no artigo de Dominichi Miranda de Sá sobre o médico. Quatro anos antes do discurso de Miguel Pereira, Arthur Neiva e Belisário Penna (este último também objeto de um perfil no livro, escrito por Luiz Antonio de Castro Santos e Regina de Figueiredo) empreenderam uma expedição pioneira ao Piauí, Pernambuco, Bahia e Goiás, a qual "provava” a absoluta precariedade dessas zonas do interior. Mais do que isso, o relatório resultante da expedição "apresentou os sertanejos como atrasados, indolentes, fatalistas e fracos porque sofreriam de doenças plenamente evitáveis, como a ancilostomose, impaludismo e doença de Chagas", escreve Sá (p. 120). O argumento não poderia ser mais polêmico, encontrando adversários em campos muito distintos.

Por um lado, ao identificar o problema do "atraso" na precariedade sanitária, essa perspectiva se opunha às teses que viam no "atavismo" das raças mestiças (predominantes no interior do país) sinal de sua fraqueza e inferioridade - o caso mais emblemático é o de Nina Rodrigues, como podemos ler no artigo de Lilia Schwarcz a ele dedicado, e também de Renato Kehl, que uniu higienismo e eugenismo, como demonstra Vanderlei Sebastião de Souza. No caso específico de Nina Rodrigues, a distinção entre "dois Brasis" não seria redutível a um país litorâneo e mais bem equipado em termos de políticas públicas e outro interiorano e abandonado à sua própria sorte, mas deveria ser compreendido através das "diferenças ontológicas" entre raças (p. 4), emblematicamente representadas em sua defesa de dois códigos penais distintos para realidades raciais também distintas.
Um segundo contraponto, no entanto, imediatamente surgiu tanto à tese de Miguel Pereira quanto aos resultados das pesquisas de Arthur Neiva e Belisário Penna. Como novamente lemos no artigo de Sá, médicos goianos e militares que participaram de outra missão ao interior do país, a Comissão Cruls, procuraram sistematicamente criticar e estabelecer versôes alternativas do "Brasil como imenso hospital". A partir de outras interpretaçôes médicas, que eram também do Brasil, procuravam mostrar que não somente o Planalto Central era das áreas mais salubres do país, como as críticas do relatório Neiva-Penna não passavam de enorme preconceito e ignorância da "ciência oficial de Manguinhos" contra a região. Para esses médicos, o grande problema do sertáo goiano seria muito mais geográfico, dada sua falta de comunicação com o restante do país. Ainda segundo os críticos, era preciso povoar o interior, fazer da região o verdadeiro coração do Brasil, inclusive anunciando a proposta de transferência da capital. Como resume a autora, "o 'imenso hospital' acabou por projetar o Brasil central na cena pública como destino do centro político do país" (p. 123).

Não é por acaso, portanto, que a concretização mais visível em termos políticos desse debate se dê justamente nas mãos de um médico-presidente. Como mostra Gilberto Hochman no capítulo dedicado a Juscelino Kubitschek, no que concerne à saúde pública, o programa (pioneiro, destaca o autor) do ainda candidato deu-se em direto diálogo com a tese de Miguel Pereira. Sua visão, no entanto, era mais positiva, procurando indicar de que maneiras a saúde pública fora (e ainda seria) capaz de tratar as mazelas identificadas pelo diagnóstico dos sanitaristas do início do século ("o Brasil não é só doença", lemos no "Programa de Saúde" anexo ao perfil). Contudo, nota Hochman, ainda era visível a persistência do euclidiano dualismo litoral/ sertão, principalmente na ênfase que conferia JK às "doenças do homem do interior" e na sua necessidade de frisar o desconhecimento que os homens e mulheres das grandes cidades brasileiras possuíam do sertanejo, ora visto em termos francamente negativos (como indolente), ora glorificado por seu heroísmo resistente. Não custa lembrar, era precisamente o oximoro a figura de linguagem preferida 
de Euclides da Cunha, capaz de criar imagens como a do "Hercules-Quasímodo", para definir o sertanejo, ou "Troia de Taipa", ao falar de Canudos.

A representação do "Brasil como imenso hospital" é emblemática tanto porque demonstra a presença das formas com que o país foi interpretado por algumas das mais importantes pesquisas e perspectivas médicas da primeira metade do século XX, como porque demonstra que os próprios cientistas (e aqui estamos falando de instituiçóes das mais rigorosas, como Manguinhos, por exemplo) eram polemicamente obrigados a pensar e refletir sobre a sociedade brasileira, e cada interpretaçáo implicava posiçóes distintas sobre a saúde e a doença.

$\mathrm{O}$ caso em que esse nexo entre medicina e interpretações do Brasil torna-se mais evidente, porém, é o de Carlos Chagas, também membro do Instituto Oswaldo Cruz. Poucos pesquisadores foram mais atinados com as grandes teses e achados científicos de seu tempo do que Chagas, cuja fama ultrapassou ainda em vida as fronteiras nacionais. No capítulo escrito por Simone Kropf lemos o quanto suas pesquisas e descobertas estiveram marcadas pelas novas teorias da microbiologia e da medicina tropical (sobretudo de Patrick Manson), opondo-se às doutrinas miasmáticas que viam no clima um fator de determinação direta das doenças. Se as discussóes contemporâneas que ocorriam nos mais avançados centros europeus aparelhavam o médico brasileiro, a situação nacional, e inclusive pós-colonial, conferia importantes particularidades a sua empreitada científica. Isso porque a ideia de uma "medicina tropical", longe de ser unânime, era altamente problemática por conta da carga que o adjetivo "tropical" carrega.

A medicina tropical surgiu na Europa no contexto da expansão colonial como uma modalidade médica capaz de auxiliar o projeto colonialista em climas considerados "hostis" (Arnold, 1996) . Em contrapartida, uma importante tradição brasileira das primeiras décadas do século XX rejeitava a necessidade de cadeiras universitárias ou linhas de pesquisa marcadas exclusivamente por esse epíteto. Era o caso de Afrânio Peixoto (analisado por Flávio Edler) e Juliano Moreira (que tem o perfil assinado por Magali Engel), cujos textos consideravam que o Brasil náo teria doenças específicas e que afirmar isso seria contribuir para estereótipos que, no limite, condenavam o país ao atraso. Chagas, porém, tanto ressignifica o caráter colonialista da medicina tropical quanto náo a reduz à chave negativa apontada por Peixoto e Moreira. Como resume Kropf, "Chagas conferia outros conteúdos à ideia de 'tropical', na medida em que significaria a possibilidade de pensar a própria nosologia brasileira na chave positiva de uma intervenção civilizatória” (p. 203), uma vez que obter conhecimentos precisos sobre doenças como a malária ou a febre amarela permitiriam ao país livrar-se, finalmente, de suas amarras e caminhar em direção ao progresso.

O livro organizado pro Lima e Hochman traz ainda casos em que medicina e interpretação do Brasil se encontram de formas mais inesperadas, não em tratados médicos, nem em escritos políticos, muito menos em ensaios. É o que ocorre, por exemplo, na literatura. Se, por exemplo, Mendes Fradique estivesse naquele nosso bar imaginário do início desta resenha, certamente daria piada. Boêmio e pândego contumaz, Mendes Fradique foi nada menos do que lente de história da medicina na Faculdade Fluminense, como podemos ler no artigo de Isabel Lustosa. Apesar do exercício regular da profissão, suas crônicas e seu único romance, Dr. Voronoff, conformaram um sarcástico painel da classe médica de seu tempo, mas também expressam, nota a autora, uma visão de mundo conservadora e elitista, com condenaçóes a experiências estéticas modernas, como o jazz e o futurismo, ou populares, como o carnaval (Mendes Fradique era um entusiasta do minueto), além de manter um forte teor de preconceito racial.

Outras, porém, são as formas de medicina, literatura e interpretação do Brasil se conectarem. É o caso de Pedro Nava, também médico profissional ao longo de toda vida e importante historiador da medicina brasileira, embora especializado desde os anos 1940 na área de reumatologia. Clínico, professor e pesquisador com uma impressionante produtividade de artigos científicos, Nava não apenas tematizou questōes médicas em suas Memórias, mas também incorporou nelas uma série de categorias tomadas de empréstimo da medicina, principalmente das práticas popular, que desempenham um "papel interno" em sua estruturação, conforme sugere André Bote- 
lho em seu texto. Ao mobilizar nas Memórias essas categorias da medicina popular, Nava teria sido capaz de articular, do ponto de vista formal, "o vínculo sensível e incontornável entre o microcosmo e o macrocosmo, entre o corpo humano e o universo" (p. 398), realizando assim uma das principais e mais inventivas qualidades de seu texto, como tem assinalado a crítica literária. Mais do que isso, a valorização do popular e suas "formas de classificação" (diriam Durkheim e Mauss) implica, nota Botelho, uma interessante atualização da agenda cultural e política modernista, cujo principal objetivo esteve no esforço de tornar o Brasil mais familiar aos brasileiros. Vejamos que em Nava e Mendes Fradique as concepçóes de medicina, sociedade e cultura, todos elementos indissociáveis, não poderiam encontrar configurações mais distintas.

Mais próximo de Nava está outro mineiro, seu contemporâneo na Faculdade de Medicina de Minas Gerais, João Guimarães Rosa. Considerado um dos maiores escritores brasileiros, é verdade que o autor de Sagarana pouco exerceu a profissão médica, debandando logo para a diplomacia, que talvez lhe permitisse dedicar mais tempo à atividade literária. Mas como nos mostra Nísia Trindade Lima, a perspectiva médica jamais o abandonou. Por exemplo, o capítulo discute como estão figuradas no tema de alguns de seus contos muitas das questóes caras à medicina brasileira nos anos de formaçáo de Rosa, sobretudo a medicina tropical e os problemas das grandes endemias rurais, que serviram como fonte de inspiração para a construção das histórias e para a problematização das relaçóes sociais no mundo sertanejo.

A categoria-chave utilizada pela autora é a de "código do sertão", da socióloga Maria Sylvia de Carvalho Franco, muito inspirada, aliás, na obra roseana, que recusa visóes disjuntivas entre tradição e modernidade (e, portanto, entre rural e urbano), pensando muito mais em termos de uma "unidade contraditória”. Assim, um livro como Grande sertão: veredas jamais poderia ser resumido sob o epíteto de "romance regionalista", pois são justamente seus "vários planos escalonados" (p. 512) que perfazem sua complexidade. Mas Lima nos mostra como é no aspecto propriamente formal da narrativa, mais do que no temático, que a força da medicina sobressai de modo mais criativo. Tomando a obra-prima de Rosa como referência, a autora sugere como é a experiência da malária que funciona como "dispositivo a permitir a passagem de um a outro plano narrativo" do livro (p. 512): entre o sertão humano, o sertão regional, o sertão metafísico e o sertão da formação social e política brasileira. Médico de formação, ao trabalhar a doença ficcionalmente o escritor opera uma interessante passagem da perspectiva do médico para a do doente, em que a malária passa a ser encarada não somente enquanto uma enfermidade, mas como uma espécie de "transe" que faz com que a realidade possa ser vista de modos diferentes, mágicos, únicos.

Seria impossível, em somente uma resenha, abordar todos as nuances e aspectos contemplados nos 29 capítulos do livro. Contudo, ao final da leitura, a noção mesma de "médicos intérpretes do Brasil" pode ser vista a partir de dois grandes ângulos. São médicos que, além de clinicarem ou fazerem pesquisas na área de saúde, se preocuparam em observar aspectos mais amplos da sociedade, chamando a atenção para como a medicina dela faz parte. Mas se suas interpretaçóes do Brasil estão carregadas de lógicas, conjunturas e jargóes médicos, também é preciso perceber como a própria medicina dos autores estudados está travejada pelo imaginário sobre o país construído tanto por eles quanto pelos contextos sociais e tradiçôes intelectuais em que se inseriam. Interpretaçóes e práticas médicas, portanto, se interpenetram mutuamente. Afinal, como sustenta Elide Rugai Bastos na orelha da obra, "as relações, as instituiçóes e os processos político-sociais não estão descolados das interpretaçóes que recebem". Na aposta certeira dos organizadores pela pluralidade de Médicos intérpretes do Brasil, percebemos claramente como são, na verdade, muitas medicinas, muitas interpretaçôes e, por consequência, muitos Brasis diferentes os que estão em jogo.

\section{Bibliografia}

ARNOLD, D. (org.) (1996), Warm climates and western medicine: the emergence of tropical medicine, 1500-1900. Amsterdã/Atlanta, Brill/ Rodopi. 
LIMA, N. T. (2013), Um sertão chamado Brasil. São Paulo, Hucitec.

ANDRE BITTENCOURT

é doutor e mestre em sociologia pelo

Programa de Pós-Graduação em

Sociologia e Antropologia da Universidade

Federal do Rio de Janeiro (UFRJ).

Autor de $O$ Brasil e suas diferenças: uma

leitura genética de Populaçóes meridionais

do Brasil (Hucitec, 2013).

E-mail: andrevbitt@gmail.com.

DOI: $10.17666 / 329518 / 2017$ 